\title{
Life Cycle Analysis for Algae Biofuels- Using Local Situations to Factor in the Cost/Benefit of High-End Products Along with Nutrient Remediation and $\mathrm{CO}_{2}$ Sequestration
}

\author{
John Korstad ${ }^{1 *}$ and Joe T Moore ${ }^{2}$ \\ ${ }^{1}$ Deptartment of Biology, Oral Roberts University, USA \\ ${ }^{2}$ KBI-Best Technologies, USA \\ *Corresponding author: John Korstad, Department of Biology, Oral Roberts University, Tulsa, USA

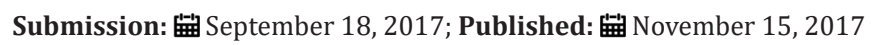

\begin{abstract}
Algae as a feedstock for commercial biofuels is best suited for sunny and warm areas with abundant fresh, salt, or brackish water. Optimum areas worldwide are in the tropics. Logical areas in North America include the Southeast Gulf coast and perhaps New Mexico. Additional practical areas on smaller scale probably lie in metropolitan locations, especially near international airports. The cost-benefit of these endeavors can be enhanced when factors such as high-end products alongside collaboration with sewage treatment or other waste water remediation, industrial carbon dioxide sequestration, reduced transport distance of fuels, and other aspects of the local economy are taken into consideration. This paper discusses how Oral Roberts University and KBI-Best Technologies propose to work with the Tulsa Airport Authority, the City of Tulsa, and local industries to enhance the practicality of a local algae biofuels venture.
\end{abstract}

Keywords: Biofuels; Algae; Airports; $\mathrm{Co}_{2}$ Sequestration; Nutrient remediation

Introduction

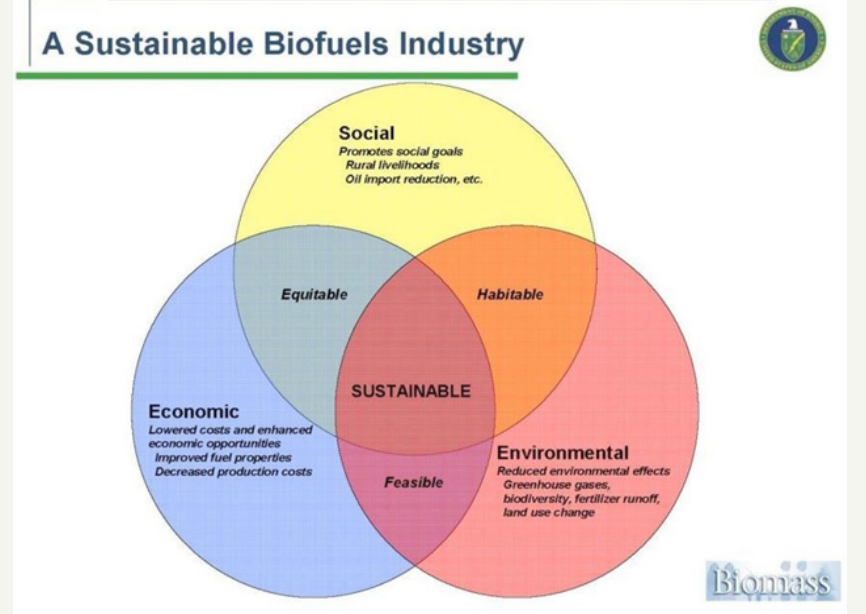

Figure 1: Sustainable biofuels must take into consideration the economic, social, and environmental impacts.

With the increasing numbers of humans on our planet comes a greater need for energy to survive and advance. This worldwide "gap" between adequate, readily available, affordable, and nonpolluting sources of energy vs. increasing need for energy is becoming alarmingly wider every year. This gap can be narrowed or slowed down in various ways such as through decreased energy use; insights and developments on how to consume energy more efficiently; exploration for added fossil fuel sources (eg, deep well drilling, oil shale, coal, fracking, etc.); and finding alternative sources of energy (eg, solar, wind, geothermal, nuclear, hydroelectric, and biofuel). The social and environmental impacts of energy sources and use must also be considered so that human energy use is as efficient, non-conflicting, and sustainable as possible (Figure 1) [1].

The aviation industry is leading the way in developing renewable sources of aviation fuel. There are research activities on every continent looking for the most economic and sustainable process. The reason that the aviation industry is so determined is because fuel cost represents the majority of the operations cost. Each added penny per gallon in the price of jet fuel translates into $\$ 175$ million of additional operational costs annually for U.S. airlines [2]. The volatility of the energy market takes a toll on the industry every time energy prices rise sharply. Another reason for the urgency is the recent and pending regulations that have been 
implemented and recently announced, which impact industry. Directive 2008/101/EC of the European Parliament and Council agreed that from 2012, all airlines flying within or into Europe had to buy $\mathrm{CO}_{2}$ allowances on the open market or reduce their GHG emissions to $97 \%$ of average annual emissions for the year 2004 2006 and this is lowered to $95 \%$ as from 2013 [3].

The US Federal Aviation Administration (FAA) has set a goal for the US aviation industry to consume one billion gallons of renewable jet fuel each year from 2018 onwards (FAA, 2011, p.10). This goal is an aggregate of renewable fuel targets for the US Air Force, the US Navy, and US commercial aviation. The renewable fuel target for commercial aviation represents $1.7 \%$ of predicted total fuel consumption by US airlines in 2018. The aviation biofuel goal is set against a backdrop of a renewable fuel standard for ground transportation, which sets minimum annual volume requirements for use of advanced biofuels and total renewable fuels that must be used through to 2022 [4].

The Obama administration on June 10, 2015 released a scientific finding that greenhouse gases from aircraft pose a risk to human health, paving the way for regulating emissions from the U.S. aviation industry. Airlines produce about $11 \%$ of the country's greenhouse gases from transportation sources, or about $3 \%$ of total greenhouse-gas emissions, according to an analysis of EPA data by the International Council on Clean Transportation [5]. Renewable fuel development is the most economical way to meet these existing and new emission regulations.

United Airlines announced in July 2015 that it would invest $\$ 30$ million in a program that would produce jet fuel from trash. Pleasanton, California-based Fulcrum BioEnergy specializes in producing both aviation and diesel fuel from ordinary household waste. The company has committed to produce as much as 180 million gallons of this fuel per year. Fulcrum's process, according to spokesperson Karen Bunton, "has been thoroughly vetted by numerous third parties including the U.S. Department of Defense and the U.S. Department of Agriculture" and has been found to meet "all of the aviation industry and military technical requirements and specifications" [6].

In July 2015 The Energy Department announced six projects that would receive up to $\$ 18$ million in funding to reduce the modeled price of algae-based biofuels to less than $\$ 5$ per gasoline gallon equivalent (gge) by 2019.

These awards included:

A. Producing Algae and Co-Products for Energy (PACE), Colorado School of Mines, Golden, CO. Colorado School of Mines, in collaboration with Los Alamos National Laboratory, Reliance Industries Ltd., and others, will receive up to $\$ 9$ million to enhance overall algal biofuels sustainability by maximizing carbon dioxide, nutrient, and water recovery and recycling, as well as bio-power co-generation.

B. Marine Algae Industrialization Consortium (MAGIC), Duke University, Durham, NC. Duke University will receive up to
\$5.2 million to lead a consortium including University of Hawaii, Cornell University, Cellana and others to produce protein-based human and poultry nutritional products along with hydrotreated algal oil extract [7].

The race for alternative sources of energy is picking up worldwide, with informed concerns voiced by experts such as Rex W. Tillerson, ExxonMobil Chairman and CEO: "In the decades ahead, the world will need to expand energy supplies in a way that is safe, secure, affordable and environmentally responsible. The scale of the challenge is enormous and requires an integrated set of solutions and the pursuit of all economic options" [8].

To break the U.S. dependence on imported petroleum for producing various liquid transportation fuels, numerous initiatives for biofuels development are underway. The Energy Independence and Security Act of 2007 (EISA) specifies a target quantity of 36 billion gallons of renewable fuels (Renewable Fuels Standard or RFS) to be annually produced in the U.S. by 2022. Of this amount, 21 billion gallons would come from advanced biofuels; 16 or more billion gallons of the 21 billion gallons is to be provided by cellulosic ethanol and the balance would come from other advanced biofuels.

Biopower is electricity produced from a wide range of biomass resources. The use of biopower is one way to help meet national goals for the use of clean, renewable energy (e.g., Renewable Portfolio Standards or RPS). Biomass is a base load renewable energy source that is readily available across the U.S. Biomass offers a renewable energy solution in areas where other renewable are not available. To achieve these goals, it is essential to ensure that cost competitive feedstock's of appropriate quality for bioenergy production are widely and sustainably available in sufficient quantities. Because the feedstock cost is a major element in the production of bioenergy, research is needed to ensure the costeffective supply of major biomass resources to biorefineries, so that they can be converted to biofuels, biopower, and bioproducts.

One of the fastest developing areas of alternative energy sources is biofuels, where the ultimate source is "organic"-i.e., of biological origin such as used cooking oil, plant seed, plant biomass, sewage, landfill, etc. Plant biomass includes terrestrial and aquatic sources, with the latter represented by algae. Microalgae are particularly attractive sources of sustainable energy for a multitude of reasons summarized in Table 1.

Companies such as Synthetic Genomics in partnership with ExxonMobil [8], Sapphire Energy [9], Algenol [10], Solarzyme [11], Petro Algae [12], Solix Biofuels [13], Origin Oil [14], Cellana [15], Solix Biosystems [16] and others have made rapid advances in developing commercial operations that are economically viable, expandable, adaptable, and environmentally sound. Some of these companies are focusing on genetically modified algae while others are seeking other ("added") benefits (eg, CO2 sequestration and/or nutrient remediation) or higher-value products that can be produced from algae such as nutritional supplements, pharmaceuticals, and omega-3 fatty acids. 
Table 1: Microalgae are particularly attractive sources of sustainable energy for a multitude of reasons.

\begin{tabular}{|c|c|}
\hline S.no & Benefits of Using Algae for Biofuels \\
\hline 1 & Non-competitive with food crops and land use (as long as ponds aren't built on agricultural land). \\
\hline 2 & $\begin{array}{r}\text { By most, but not all, estimates, prospective/proven oil content from algae biomass is orders of magnitude higher than from other feedstock's } \\
\text { like corn, sugar cane, Jatropha, etc. }\end{array}$ \\
\hline 3 & $\begin{array}{r}\text { Algae need } \mathrm{CO}_{2} \text { to photosynthesize and can thus be used to sequester } \mathrm{CO}_{2} \text { from industrial sources of flue and flaring gas. Algae-based fuels } \\
\text { are thus C-neutral or even C-positive (i.e., more C-capturing than releasing). }\end{array}$ \\
\hline 4 & $\begin{array}{r}\text { Algae can be used to remediate high-nutrient water sources such as sewage treatment plants, agricultural runoff, and landfill leach ate basins. } \\
\text { This linkage not only cleans up the water but may also lower the cost for nutrients needed to culture algae. }\end{array}$ \\
\hline 5 & $\begin{array}{r}\text { End-products can be biofuel along with other higher value products such as feed (protein), cosmetics, pharmaceuticals, and health-related } \\
\text { products (e.g., omega-3 fatty acids). }\end{array}$ \\
\hline 6 & $\begin{array}{r}\text { Different species of algae can be grown in polluted, saline, brackish, and freshwater. } \\
\text { Algae can be used as one component of an aquaculture-centered system where fish like Tilapia are grown for food in a recirculating and } \\
\text { hydroponic system. }\end{array}$ \\
\hline 8 & $\begin{array}{r}\text { Algae don't contribute to acid deposition (ie, no SO }{ }_{2} \text { emissions). } \\
\text { nitrogen and eliminating or at least lessening the need for nitrogen fertilizers. This can help reduce the need for nitrogen fertilizers and, } \\
\text { more importantly, remediate water pollution and help confront the expanding "Dead Zone" in the Gulf of Mexico. }\end{array}$ \\
\hline 9
\end{tabular}

Thorough reviews on the culture, harvest, conversion, and practical use of algae for biofuel and other products are given by Chisti [17] \& Sharma et al. [18]. Informative "life cycle analyses" that evaluate all of the pros and cons of selected pathways for biofuel production must be utilized and closely evaluated [19]. Some lifecycle analyses express concern for water usage for biofuels (EROWI = energy return on water investment). Corn to ethanol, Jatropha, and other non-algae plant feedstock for biofuels use too much water (as does fracking!), fertilizers, agricultural land, and energy, and thus give a "bad name" for biofuels. Algae, particularly when grown in saline/brackish or polluted waters (eg, wastewater), have a much more positive "scorecard", but the public doesn't always get to hear about the benefits of algae vs. the "concerns" of biofuels in general. There's still a lot of needed "unpacking" and clarification!

Economical, substantial, reliable, and dependable (uninterrupted) sources of fuel are especially important to a nation's military and airlines. Organizations such as the Commercial Aviation Alternative Fuels Initiative (CAAFI) have "sought to enhance energy security and environmental sustainability for aviation by exploring the use of alternative jet fuels" [20]. The needs of each airport will vary depending on local weather, infrastructure, needs, available feedstock, carbon dioxide and nutrient sources, and other factors [21].

In order to meet the sustainability goals outlined in the beginning of this paper, an algae aviation fuel production concept must overcome the economic barriers that have been identified by previous studies. One study's projected cost of algae produced in a raceway is $\$ 0.15$ to $\$ 0.20$ per pound and $\$ 1.95$ per pound when produced in a photo bioreactor (PBR). This compares to $\$ 0.10$ to $\$ 0.20$ per pound for wood pellets delivered to UK power plants [22]. Most of the cost difference between raceway and PBR is capital only. Other significant costs when using algae biomass as a feedstock for fuel production are dewatering and transportation. All these things identify a need to optimize the production, dewatering, processing and transportation methods for Algae Aviation Fuels, (AAF), projects.

\section{Practical Model for Metropolitan Areas}

This paper proposes a practical model for Tulsa, Oklahoma and other metropolitan areas to produce biodiesel and jet fuel from algae using waste carbon dioxide and nutrients from local sources. We propose to use algae to produce up to $50 \%$ of the aviation fuel consumed by the Tulsa Airport by utilizing up to 1700 acres of adjacent land to the North, East and South of the Airport that cannot be used for other development purposes. These lands could produce up to 15-million gallons of Bio-Aviation fuel and 100 million pounds of feed products annually and generate up to $\$ 60$ million in annual revenue.

We - Joe Moore, owner of KBI-Best Technologies (a local company, hereafter called KBI) and John Korstad (Professor of Biology at Oral Roberts Univ., hereafter called ORU) - have been working together on algae production and processing for five years. We have been growing algae at the KBI plant and working closely with the Tulsa Airport Authority to use lands surrounding the airport to grow and process the algae oil into bio-aviation fuel.

As a result of the five years of research effort, a process has been developed that addresses the challenges faced by the aviation industry as it searches for a sustainable renewable fuel source. The resulting AAF process is a combination of several proven technologies and some unique process that have been developed over the last five years. The centerpiece of the process is the former Air Force Plant \#3 Industrial Waste Treatment Plant, (IWTP). This seven acre, fifteen million dollar facility, adjacent to the Tulsa International Airport, (TUL), will act as the processing hub of the algae growing and nutrient gathering processes. The IWTP plant proximately to waste treatment, waste disposal, CO2 Source, growing acreage and fuel delivery point makes it an ideal location 
for the collection and processing of algae and producing aviation fuel along with associated high value co-products.

An important part of AAF process is the ability to produce the required electrical power and heat on site, using the renewable byproducts of the algae processing. With the products of combustion being water, carbon dioxide and nitrogen compounds, they serve to provide the return of nutrients and compounds back to the algae growing system. A conventional electrical cogeneration process, using internal combustion engines fueled by synthesis gas from reactors drive generators and produces heat from exhaust and jacket water. The acreage surrounding TUL will require investment to produce the quantity of algae necessary to feed the process. Open ponds are not recommended around airports due to the waterfowl that can concentrate and interfere with air traffic. An integrated algae growing system (IAGS), is proposed that will provide a closed system for the optimum production of selected algae species. A small scale IAGS is planned to determine the installation and operational cost. The goal is to achieve capital and operation costs similar to the raceway approach.

The collection and initial dewatering of the algae will be performed in existing tankage and clarifiers located on the IWTP property. Algae bearing water will be circulated through the system, reducing the concentration and adding the required nutrients and compounds, before the slurry is sent back to the IAGS. The concentrated algae will be stored in existing tankage, where it will be either sent to existing filter presses for further concentration into a cake or fed to the algae slurry processing system. The drying of the filter cake for oil removal takes a great deal of heat and can be the single highest operating cost in the process. Sufficient dry algae must be diverted from fuel and feed production, in order to operate the electrical cogeneration process and produce the necessary heat to dry the algae.

In addressing the problem of drying the algae for oil separation, we were faced with the cost and time constraints associated with dewatering and drying. A method was sought that would allow oil separation without requiring dewatering. A theoretical approach was proposed that would take the water containing concentrated algae and heating it in a pressurized vessel to achieve oil separation as demonstrated by researchers. Kusdiana \& Saka [23], Pinnarat [24], Savage \& Rebacz [25], Brown \& Duan [26]. Their findings have shown that this "pressure cooker" process effectively decomposes all of the algal cell constituents (lipids, proteins, and carbohydrates); releases hydrogen, carbon monoxide, carbon dioxide, methane and other hydrocarbons; and ultimately releases more total energy. This depolarization process is applicable for other feedstocks such as switch grass, crop residue, livestock waste, food waste, and woody biomass.

Another improved but more expensive method of concentrating algae from water is offered by the Origin Clear Company [27]. The technical approach proposes to use participating Oral Roberts University (ORU) Biology, Chemistry, and Engineering faculty to outline and evaluate possible methods for the preparation, processing and measurement of conversion products. Initial analysis will be performed to determine biomass conversion at various temperatures and pressures. Different types of biomass will be tested for the extent of depolymerization at varying temperatures, pressures and concentration. Once university results are accumulated and evaluated, KBI will build a pilot-sized reactor and run the tests at larger quantities and under process plant conditions. The results of these tests will be compared to the laboratory scale tests, and a scale up version of the system will be developed for a small-scale operational proof of concept. These results will lead to a final design for production of 1000 tons per day.

In the case of high oil bearing algae strains, the economics of drying the algae may prove to be outweighed by the improved efficiency of oil extraction. In this case, algae will be mechanically or chemically processed to extract the oil. The remaining dried algae can be used as high value products such as nutritional supplements, animal or fish feed, pharmaceuticals or further processed in a thermal reactor. Once the oil is extracted by either the wet or dry method, it must be further processed to produce the aviation fuel. There are currently three main research strategies for alternative aviation fuels as following: fatty acid esters (FAEs), hydro processed renewable jet - synthesis paraffin kerosene (HRJ - SPK), and FischerTropsch jet - synthesis paraffin kerosene (FTJ - SPK). FAEs, which are produced like biodiesel, derived from the transesterification of the triglycerides and fatty acids in algae, vegetable, animal or waste oils. It uses simple technology, with low cost and high efficiency [28]. A complete evaluation of these technologies is being made, and a selection will made based on the best performance and required capacity.

HRJ - SPK is produced by hydrogenative refining of the triglycerides and fatty acids in the vegetable, animal or waste oils. HRJ production firstly requires deoxygenation of triglycerides and fatty acids to produce C8-C22 normal paraffin. In a second step, the resulting hydrocarbons are further cracked and isomerized to reduce the carbon number of the paraffin's into the boiling range of the jet fuel (number of carbon C8-C16). Honeywell's UOP is currently the only large-scale producer of HRJ [3].

FTJ -SPK is produced from coal, biomass, or natural gas feedstock through gasification followed by Fischer-Tropsch synthesis process. The synthesis gas (i.e., mixture of carbon monoxide and hydrogen) produced in the gasification process is then catalytically reacted to form a mixture of long-chain paraffin's in the Fischer-Tropsch synthesis process. These products are further hydro processed such as through HRJ [3]. To further optimize the AAF process, we propose to use nutrients and carbon dioxide from local sources to promote algal growth while also lowering wastewater and flue gas emissions, and ultimately lowering the cost of not only culturing the algae but also meeting EPA mandates for water and air quality [29]. Potential local sources of nutrients include wastewater effluent from the City of Tulsa's Northside sewage treatment plant [30], Waste Management's Quarry Landfill [31], and American Environmental Landfill [30]. Potential local sources of $\mathrm{CO}_{2}$ include 
flue gas from the Eagle Materials Cement Plant [32] and Holly Refinery [33].

\section{Benefits}

The benefit of the successful implementation of this proposal will hopefully lead to a cheaper, more dependable, more plentiful, more environmentally favorable, and thus more sustainable source of jet fuel. This will go a long way toward lessening the problems discussed earlier. Further benefits include gaining additional experience in these complex processes, and gaining ideas on how to improve the production process of biofuels from algae. This information will also be used to augment and improve the information facilitated in various courses at ORU. Student interns will benefit from being mentored by the knowledgeable people at industries and facilities involved in this project, and from the general research experience that will culminate with their Senior Research Paper. Student interns can also collaborate with professors and industry personnel in presenting their results at professional meetings and submitting research papers to professional journals. The personnel at local industries involved with this project will also benefit from this collaboration through use their equipment and expertise to test better methods of producing or procuring renewable energy.

\section{Technical Objectives}

The technical objectives of this project are as follows:

A. Determine the extent of depolymerization that occurs for algae and other biomass in water solutions at various concentrations, temperatures, and pressures.

B. Determine the energy balance of the process and determine optimum set points for a laboratory scale proof of concept.

C. Determine the process and practicality of utilizing nutrients and $\mathrm{CO} 2$ from local sources.

D. Determine methods to produce additional, higher-value products that can be produced from algae and other feedstock such as nutritional supplements, pharmaceuticals, and omega-3 fatty acids.

E. Determine overall economic benefits of this process at various plant sizes, using a variety of feed stocks.

F. Complete preliminary design for construction and evaluation of a pilot scale process for this proposal.

\section{Overall Goal and Conclusion}

The overall goal of this project is to develop a simple and efficient process that can be shared with a wide group of people - university researchers; business people in the energy industry; farmers and ranchers; government officials and staff; the National Energy Policy Institute [34], which is located in Tulsa and has national and international influence; and the general public. Our hope is that, together, we can lessen our dependency on foreign oil by developing abundant local sources of energy that are non-polluting (sequestering vs. releasing nutrients and carbon dioxide), don't compete with food sources for human and animal consumption (e.g., corn), are competitive or even favorable to current fossil fuels, and help improve the local economy.

\section{References}

1. Goss-Eng A (2008) Sustainable biofuel production-a US DOE perspective.

2. Glover BM (2011) Homegrown biofuels are critical to the future of flight. Herald Net, USA.

3. Hong TD, Soerawidjajab TH, Reksowardojoa IK, Fujita O, Dunianid Z, et al. (2013) A study on developing aviation biofuel for the Tropics: Production process-Experimental and theoretical evaluation of their blends with fossil kerosene. Chemical Engineering and Processing 74: 124-130.

4. Winchester N, McConnachie D, Wollersheim C, Waitz IA (2013) Economic and emissions impacts of renewable fuel goals for aviation in the US. Transportation Research Part A 58: 116-128.

5. Jansen B (2015) EPA takes first step to limit greenhouse-gas emissions from airlines, USA Today.

6. Siegel RP (2015) Green Aviation Climbs to New Heights. ENN, China.

7. Energy Gov (2015) Energy Department Awards \$18 Million to Develop Valuable Bioproducts and Biofuels from Algae.

8. Exxon Mobil (2011) The Outlook for Energy: A View to 2040. pp. 1-52.

9. http://www.sapphireenergy.com/

10. http://www.algenolbiofuels.com/

11. http://solazyme.com/

12.http://www.petroalgae.com/

13. http://www.solixbiofuels.com/

14. https://www.originclear.com

15. http://cellana.com/

16. http://www.solixbiosystems.com/

17. Chisti Y (2007) Biodiesel from microalgae. Biotech Adv 25(3): 294-306.

18. Sharma YC, Singh B, Korstad J (2011) A critical review on recent methods used for economically viable and eco-friendly development of microalgae as a potential feedstock for synthesis of biodiesel. Green Chem 13: 2993-3006.

19. Clarens AF, Resurreccion EP, White MA, Colosi LM (2010) Environmental life cycle comparison of algae to other bioenergy feedstocks. Environ Sci Technol 44(5): 1813-1819.

20. Slade R, Bauen A (2013) Micro-algae cultivation for biofuels: Cost, energy balance, environmental impacts and future Prospects. Biomass and Bioenergy 53: 29-38.

21. CAAFI (2011) Commercial Aviation Alternative Fuels Initiative. p. 1.

22. Mulder J (2010) What does alternation aviation fuel have to do with the future of your airport? Airport Magazine 2011: 25-26.

23. Kusdiana D, Saka S (2004) Effects of water on biodiesel fuel production by supercritical methanol treatment. Bioresource Technol 91(3): 289295

24. Pinnarat T, Savage PE (2008) Assessment of noncatalytic biodiesel synthesis using supercritical reaction. Ind Eng Chem Res 47(18): 68016808.

25. Savage PE, Rebacz N (2010) Water under extreme conditions for green chemistry. In: C-J Li (Ed.), Handbook of Green Chemistr, Vol 5, Reactions in Water, pp. 1-254.

26. Brown TM, Duan P, Savage PE (2010) Hydrothermal liquefaction and 
gasification of Nannochloropsis sp. Energy Fuels 24(6): 3639-3646.

27. http://www.originclear.com/

28. http://www.epa.gov/lawsregs/.

29. https://www.cityoftulsa.org/city-services/wastewater/treatmentplants.aspx
30. http://www.aelok.com/

31. http://www.wm.com/facility.jsp?fac=S04049\&zip=74116\&cat=3

32. http://www.eaglematerials.com/products/cement.html

33. http://hollyfrontier.com/tulsa/

34. http://nepinstitute.org/ 